\title{
Apresentação
}

\section{O pirotécnico Murilo Rubião: apontamentos introdutórios}

\author{
Nessa hora os homens compreenderão que, mesmo à \\ margem da vida, ainda, vivo, porque a minha existência \\ se transmudou em cores e o branco já se aproxima da \\ terra para exclusiva ternura dos meus olhos. \\ (Murilo Rubião)
}

O fantástico instaura na ficção um efeito de estranheza que nos prende e nos desperta a curiosidade, instigando-nos à leitura ou à visão das imagens propostas na literatura, no cinema, nos filmes de animação, nas novelas gráficas e histórias em quadrinhos, enfim, em todo espaço estético no qual o insólito se planteia.

Porque procuramos e gostamos dessa estranheza? Como a recebemos e quais as emoções que nos desperta? Que tipo de emoções aqui se trata: reais, fingidas, imaginadas? Como se suscitam os efeitos de fantástico? Quais as estratégias acionadas para gerar o fantástico? Que estruturas e elementos fantásticos podemos reconhecer na ficção fantástica?

Essas são algumas de entre muitas outras perguntas que se poderiam levantar, as quais os investigadores e teóricos do fantástico tentam responder. E, como todo o fenômeno cultural é movente e dinâmico, também o fantástico vai procurando novas fórmulas e formas, tornando necessário não só procurar respostas, mas também ir levantando outras perguntas que se considerem pertinentes e possam contribuir para o estudo e o conhecimento do fantástico nas suas diferentes modalidades de apresentação.

O fantástico coloca em causa a forma convencional do nosso entendimento do espaço e do tempo, brinca com espaços irreais, joga com diferentes temporalidades, ativa conexões improváveis, propõe o impossível, ou seja, o fantástico vai para além dos limites do real, como ressalta David Roas (2011). Nesse sentido, quer a transgressão, quer a subversão constituem elementos basilares do fantástico, conduzindo o seu leitor a interrogar-se sobre o que conhece ou pensa.

Daí que esse teórico catalão, entre muitos outros, considere a transgressão um elemento fundacional do fantástico. Por seu turno, esse ingrediente conduz a um outro sentido que 
também é fundamental: o sentido subversivo. Ao colocar em causa uma lógica natural e ao sugerir nexos impensados, o fantástico obriga a repensar o conhecimento adquirido e convencional, introduz perplexidades e orienta para interrogações várias.

O conjunto de textos aqui reunidos pretende investigar alguns desses aspetos, aplicar conceitos e teorias à análise concreta de textos fantásticos e inferir sentidos relevantes a partir da interpretação de elementos e estratégias identificadas nos textos abordados. O foco de seleção do presente dossiê é a obra do escritor mineiro Murilo Rubião, cuja maestria das técnicas e estratégias ficcionais do insólito é sumamente reconhecida, fazendo com que a sua obra figure como referência para os críticos, os estudiosos e mesmos para os escritores de literatura fantástica.

O jornalista e contista Murilo Eugênio Rubião nasceu no primeiro dia de junho de 1916, em uma cidade situada no sul do Estado de Minas, naquela época chamada Silvestre Ferraz e hoje conhecida como Carmo de Minas. Em 1935 concluiu o Bacharelado em Humanidades, no Colégio Arnaldo, em Belo Horizonte, e em 1942, nessa mesma cidade, formou-se em Direito pela Universidade de Minas Gerais. É na capital de Minas Gerais que desenvolveu sua principal atividade remunerativa profissional, o jornalismo, tendo sido nomeado, em 1942, Diretor da Associação de Jornalistas Profissionais de Minas Gerais. Em relação às atividades desenvolvidas, ele relata: "Comecei a ganhar a vida cedo. Trabalhei em uma baleira, vendi livros científicos, fui professor, jornalista, diretor de jornal e de uma estação de rádio. Hoje sou funcionário público" (RUBIÃO, 2018). Na Espanha, em sua breve estadia, exerceu várias funções, como chefe do Escritório de Propaganda e Expansão Comercial do Brasil, adido junto à Embaixada Brasileira, membro da delegação brasileira no Congresso de Cooperação Intelectual. Em 1966 foi responsável pela criação do Suplemento literário de Minas Gerais, publicação de enorme relevo no campo da Literatura no Brasil. Essa publicação, que circula bimensalmente encartada nas edições do Jornal Minhas Gerais, da Imprensa Oficial, ficou famosa por ter desencadeado a "Geração Suplemento", que, ao longo da segunda metade do século XX, reuniu diversos autores nacionais e internacionais, como Luiz Vilela, Jaime Prado Gouvêa, Sérgio Sant'Anna, Bueno de Rivera, Fernando Sabino, Dalton Trevisan, Paulo Mendes Campos, Carlos Drummond de Andrade, Clarice Lispector, Júlio Cortázar e Jorge Luis Borges.

De todas as atividades exercidas por Murilo Rubião foi o ofício literário que o projetou como um dos maiores escritores do século XX na América Latina. Murilo Rubião pode ser considerado o precursor da tradição do insólito não só em terras brasileiras, como também merece reconhecimento como instigador da obra de escritores responsáveis pelo boom da literatura latino-americana, como confessa Julio Cortázar, conforme relato de Remy Gorga 
Filho (apud SILVEIRA, 2012): "Ele dizia que o mineiro Murilo Rubião foi o primeiro autor do fantástico latino-americano, antes mesmo dele, Cortázar".

No ano de seu falecimento, 1991, a Secretaria de Cultura de Belo Horizonte implantou o projeto Memória viva, destinado ao estudo e à divulgação de sua obra.

Seus contos foram traduzidos para várias línguas e frequentam editoras, bibliotecas e livrarias de vários espaços do mundo, como Estados Unidos, Tchecoslováquia, Espanha, Alemanha, Venezuela, França, Polônia, dentre outros.

Antonio Candido, um dos maiores nomes da crítica literária brasileira, ressalta, em "A nova narrativa", o valor da obra de Murilo Rubião no cenário da literatura no Brasil, porquanto esse autor mineiro conseguiu arquitetar contos insólitos em um momento estético “de predomínio do realismo social, propondo um caminho que poucos identificaram e só mais tarde outros seguiram" (CANDIDO, 2006, p. 252). Candido denomina como "ficção do insólito absurdo" a escrita muriliana. Em carta datada de 1967, Candido reitera o caráter precursor dos contos de Murilo Rubião e procura definir o efeito literário gerado pelo insólito ali instaurado: "um insólito despreocupado que suprime qualquer farol e nos faz sentir como se as leis do mundo estivessem normalmente refeitas. Uma naturalidade admirável, feita de supernaturalidade" (CANDIDO, 2018).

Como podemos compreender a configuração estética dessa categoria de insólito ("insólito absurdo") planteada por Candido sobre a obra de Rubião? Seguindo a compreensão empreendida por Gama-Khalil (2016) em "Murilo Rubião nos arredores do mito e do real maravilhoso", pautamo-nos, em primeiro lugar, pela noção de insólito acionada pela orientanda de Antonio Candido, Lenira Marques Covizzi, que defende a capacidade evidenciada pelo insólito de deflagrar, quer no plano da narrativa, quer no plano da recepção o "sentimento do inverossímel, incômodo, infame, incongruente, impossível, infinito, incorrigível, incrível, inaudito, inusitado, informal" (COVIZZI, 1978, p. 26 - ênfase da autora citada), uma vez que o insólito é potencializado por meio de um acontecimento que não sói ocorrer, não encontra, portanto, existência aparente no cotidiano prosaico. Para a compreensão da noção de "absurdo", Gama-Khalil aciona um diálogo com Albert Camus, em O mito de Sísifo, uma vez que, nesse livro, o absurdo é entendido como a "densidade e a estranheza do mundo", como "esse malestar diante da desumanidade do próprio mundo, essa incalculável queda diante da imagem daquilo que somos, essa 'náusea"' (CAMUS, 2013, p. 29). A junção das duas noções articuladas por Antonio Candido parece ser suficiente para explicar o grau de estranheza gerado pelos contos de Murilo Rubião: 
[...] o que o leitor encontra nesses contos é esse sentimento inusitado que advém de uma estranheza não especificamente do fantástico que surge nas narrativas, mas de perceber que esse inusitado, esse insólito, permeia o seu dia-a-dia aparentemente tão real, contudo ao mesmo tempo tão desumano e marcado por náuseas e estranhezas. (GAMA-KHALIL, 2016, p. 49)

Alguns críticos insinuam a influência de Franz Kafka sobre a escrita de Rubião, já que a escritura de Kafka também faz irromper o insólito em meio ao estupidamente prosaico. Contudo Murilo Rubião contesta, uma vez que teve o primeiro contato com a obra do escritor tcheco apenas em 1943, ano posterior à escrita da maior parte dos contos do livro $O$ ex-mágico. Afinal quem seria precursor de quem (suscitamos aqui um diálogo irônico com o ensaio de Borges)? Rubião fala-nos desses mágicos diálogos intertextuais em sua obra e na de Kafka:

Acredito que Kafka, como eu, tenha sido influenciado pelo Velho Testamento e pela mitologia grega. O que é a Metamorfose e Teleco senão a reinvenção do mito de Proteu, pastor do rebanho marinho de Netuno, que por detestar predizer o futuro, dom que lhe fora concedido, transforma-se em animais para não o fazer. (RUBIÃO, 1986, p. 4-5)

Ainda que muitos críticos não tenham afirmado sobre a influência de Kafka em sua ficção, quase todos reconhecem a afinidade das narrativas kafkianas com as murilianas, como é o caso de Mário de Andrade (In: MORAES, 1995, p. 32): “o mais estranho é o seu [de Murilo Rubião] dom forte de impor o caso irreal. O mesmo dom de um Kafka: a gente não se preocupa mais, e preso pelo conto, vai lendo e aceitando o irreal como si fosse real, sem nenhuma reação mais".

Murilo Rubião reconhece algumas importantes vertentes dialógicas de sua obra: "Minha opção pelo fantástico foi herança de infância, das intermináveis leituras de contos de fadas, do Dom Quixote, da História Sagrada e das Mil e Uma Noites”. (RUBIÃO, 1986, p. 4). Em todos esses livros Rubião encontrou elementos que o auxiliaram na elaboração estética do insólito em sua curta mas altamente significativa obra. São ao todo trinta e três contos considerados por ele "prontos" para a publicação; entretanto o seu labor ficcional consistia na incansável reescrita desses contos. Audemaro Taranto Goulart, autor de um dos ensaios deste dossiê, em seu livro O conto fantástico de Murilo Rubião, trata assim do processo de reescritura muriliano: "Tudo quanto se cria transforma-se em algo aberto, que está constantemente exigindo novas recriações" (GOULART, 1995, p. 16).

Davi Arrigucci Jr. (1987), em Enigma e comentário, traz a noção de experiência dos apontamentos teóricos de Walter Benjamin para analisar obras de vários escritores latino- 
americanos do século XX e dedica espaço privilegiado a reflexões sobre a escrita literária muriliana. Partindo do processo metamórfico de algumas de suas personagens (recordemo-nos, por exemplo, do emblemático Teleco), Arrigucci Jr. explica que as metamorfoses ocorrem na obra de Murilo Rubião não apenas no plano temático, mas ela acontece especialmente no plano da criação: uma escrita que é criada e recriada, assumindo novas facetas, inusitadas formas, metamorfoseando-se continuamente.

Sobre o processo metamórfico de sua escrita, Murilo Rubião assim se posiciona:

Sempre aceitei a literatura como uma maldição. Poucos momentos de real satisfação ela me deu. Somente quando estou criando uma história sinto prazer. Depois é essa tremenda luta com a palavra, é revirar o texto, elaborar e reelaborar, ir para a frente, voltar. Rasgar. (RUBIÃO apud GOULART, 1995, p. 16)

O movimento de ir, voltar e rasgar-se faz-nos lembrar do estilo defendido pelo defunto-autor Brás Cubas, criado por Machado de Assis, autor por quem Rubião nutria profunda admiração literária. Recordemos o estilo de Brás Cubas: "e este livro e o meu estilo são como os ébrios, guinam à direita e à esquerda" (ASSIS, 1985, p. 80).

Flávio Carneiro metaforiza o ato da reescrita por meio da imagem de uma "parede da finitude" e, nesse sentido, consegue explicar muito sobre a escritura muriliana:

Na obra de Murilo Rubião, a reescritura aparece como mais uma volta na espiral projetad pelo autor e reflete a capacidade do texto de se superar a cada linha, buscando o espaço que aparentemente se esconde atrás da parede da finitude. Reescrever é tentar de novo a derrubada dessa parede, que outra vez se reergueu aos olhos do autor incansável. A cada surgimento do limite, o texto se realimenta. A parede existe para ser destruída parece dizer o texto, não existe para ser vista ou justificada, mas apenas para ser destruída - para, novamente parede, ser de novo ruínas. (CARNEIRO, 2013, p. 89).

Podemos definir a arte literária desse autor mineiro como uma escrita que se reinventa por todos os caminhos possíveis do insólito. Em carta a Murilo Rubião o escritor memorialista Pedro Nava (2018) escreve: “[...] agradeço a remessa de O pirotécnico Zacarias. Conto ou poesia? Poesia - porque só ela permite tanta supressão (e retomada) do Tempo e do Espaço e o uso que você faz do absurdo nosso de cada dia...”. Nava põe em relevo um aspecto singular dos contos murilianos: a conjunção fortuita entre narrativa e poesia, que, em nossa leitura, nasce de um jogo entre o dito e o não dito, entre o revelado e o encoberto, entre silêncios e palavras. Rosalba Campra, ao tratar dos territórios da literatura fantástica, dedica um capítulo aos desafios do silêncio e afirma: "Dormências oportunas. Escuridões. [...] Tematizações e 
interrupções do discurso são formas do silêncio com que o texto constrói seu sentido fantástico" (CAMPRA, 2016, p. 123). Por isso ela defende que a literatura fantástica é uma poética dos vazios, visto irromper por meio muito mais dos espaços lacunares do que dos espaços dos ditos.

O dossiê aqui apresentado reúne textos que, a partir de variadas perspectivas, deslindarão a poética desse contista de valor ímpar no cenário da literatura fantástica mundial. O artigo Murilo Rubião: teórico e crítico de sua própria escrita propõe pensar o fantástico a partir das reflexões realizadas pelo próprio Murilo Rubião, apontando que o fantástico não se alterou ao longo do século XX, mas o que há é a irrupção de uma nova forma de conceber a literatura fantástica marcada pelas mudanças socioculturais de nossa contemporaneidade. $O$ processo criativo de Murilo Rubião: a busca do sentido perdido traz a lume o procedimento literário inscrito na obra de Murilo Rubião, apontando elementos subjacentes ao texto literário e mostrando que o dizer e a produção de sentidos ultrapassam o plano das palavras. A autora de "Petúnia", de Murilo Rubião e o diálogo com os contos populares impulsiona um diálogo profícuo entre o conto "Petúnia" e os mitos e contos de fadas tradicionais, demonstrando como algumas temáticas são recorrentes na tessitura contística de Murilo Rubião. No artigo Histórias de uma fila: A fila" (1974), de Murilo Rubião, e o Brasil dos anos de chumbo, os autores ponderam sobre o momento autoritário da ditatura no Brasil a partir da narrativa fantástica de Murilo Rubião, demonstrando como é possível pensarmos nossa realidade a partir do fantástico. Em Armação de mundo possível e processos de composição de personagens insólitos em " $O$ pirotécnico Zacarias”, de Murilo Rubião, emerge a discussão acerca da composição dos mundos possíveis e insólitos na obra de Rubião, revelando como tal composição impulsiona a deflagração de uma multiplicidade de sentidos na leitura das narrativas. O artigo intitulado Sob os domínios do animal: um estudo do conto "Os dragões", de Murilo Rubião, discute as fronteiras entre imaginação e realidade a partir dos personagens animais no conto "Os dragões" do autor mineiro, marcando a potencialidade do caráter fantástico dos contos contemporâneos. Já em Os lados do círculo em "Os três nomes de Godofredo” de Murilo Rubião reflete-se sobre a narrativa de Rubião, colocando em relevo a figura geométrica do círculo e ressaltando como ela permite a inserção do leitor no texto literário. O artigo Os insólitos corpos de Murilo Rubião: uma leitura de "Bárbara" e "As unhas" permite questionar a ordem social e suas imposições, a partir da irrupção das transformações corporais insólitas que são configuradas nas narrativas do autor em foco neste dossiê. O texto Curta Murilo: Insólitas pirotecnias entre textos e tela demonstra a importância da obra de Murilo Rubião e a irrupção do insólito em suas narrativas a partir da análise de um de seus contos e da sua transposição em outras mídias, como a animação de Olímpio Costa. Por fim, o artigo Murilo Rubião e José J. Veiga e a oposição ao 
racionalismo nos contos "O lodo" e "Os Cascamorros": breves considerações reflete acerca do realismo mágico em contraposição ao racionalismo, apontando determinadas condutas e padrões ditados pelos mecanismos de poder na contemporaneidade.

A imagem de pirotécnico que escolhemos para figurar no título do dossiê que aqui se apresenta advém de um dos seus contos - "O pirotécnico Zacarias" -, e com ela pretendemos evocar a ideia de uma obra explosiva, que destronou alguns paradigmas estéticos em seu tempo e ainda vem iluminando novas perspectivas no campo da literatura fantástica. Nesse sentido, este dossiê seleciona e apresenta trabalhos que demonstram as muitas veredas insólitas e fantásticas que os contos murilianos encerram.

\author{
Marisa Martins Gama-Khalil (UFU/CNPq) \\ Maria João Simões (Universidade de Coimbra) \\ Adelaide Caramuru Cezar (UEL) \\ (Organizadoras)
}

\title{
Referências
}

ARRIGUCCI JR., Davi. Enigma e comentário: ensaios sobre literatura e experiência. São Paulo: Companhia das Letras, 1987.

ASSIS, Machado de. Memórias póstumas de Brás Cubas. Rio de Janeiro: Tecnoprint, 1985.

CAMPRA, Rosalba. Territórios da ficção fantástica. Rio de Janeiro: Dialogarts, 2016.

CANDIDO, Antonio. A nova narrativa. In: A educação pela noite. Ouro sobre Azul: Rio de Janeiro, 2006, p. 241-260.

CANDIDO, Antonio. Carta. Disponível em: <http://www.murilorubiao.com.br $>$. Acesso em: 22 nov. 2018.

CARNEIRO, Flávio. Escrever é escrever de novo: a escrita infinita em Murilo Rubião. In: GARCÍA, Flavio; BATALHA, Maria Cristina (Org.). Murilo Rubião: 20 anos depois da sua morte. Rio de Janeiro: EDUERJ, 2013.

COVIZZI, Lenira Marques. O insólito em Guimarães Rosa e Borges. São Paulo: Editora Ática, 1978.

GAMA-KHALIL, Marisa Martins. Murilo Rubião nos arredores do mito e do real maravilhoso. Literartes, n. 6, p. 46-70, dez. 2016.

GOULART, Audemaro Taranto. O conto fantástico de Murilo Rubião. Belo Horizonte: Lê, 1995. 
MORAES, Marco Antonio de (Org.). Mário e o pirotécnico aprendiz: cartas de Mário de Andrade e Murilo Rubião. Belo Horizonte: Ed. UFMG; São Paulo: Giordano, 1995.

NAVA, Pedro. Carta. Disponível em: <http://www.murilorubiao.com.br>. Acesso em: 22 nov. 2018.

ROAS, David. Tras los límites de lo real: Una definición de lo fantástico. Madrid: Páginas de Espuma, 2011.

RUBIÃO, Murilo. Autoretrato. Disponível em: $<$ http://www.murilorubiao.com.br>. Acesso em: 22 nov. 2018.

RUBIÃO. Murilo. Entrevista a J. A. de Granville Ponce. In : O pirotécnico Zacarias. São Paulo: Ática, 1986.

SILVEIRA, Nubia. Julio Cortázar, um homem amável que gostava de escrever cartas. Disponível em: $<$ http://www.sul21.com.br/jornal/2011/07>. Acesso em: 26 nov. 2012. 